\title{
Regular Leisure-Time Physical Activity Is Positively Associated With Happiness Occurrence Among Young Adults In Taiwan
}

Chien-Chang Ho ( $D$ 093703@mail.fju.edu.tw )

Fu Jen Catholic University

\section{Research Article}

Keywords: Physical activity, Exercise, Young adults, Well-being, Taiwan

Posted Date: January 17th, 2022

DOI: https://doi.org/10.21203/rs.3.rs-1238446/v1

License: (c) (1) This work is licensed under a Creative Commons Attribution 4.0 International License.

Read Full License 


\section{Abstract}

Background: This study aims to examine the relationship between regular leisure-time physical activity (LTPA) and happiness among young adults in Taiwan.

Methods: A cross-sectional nationwide study was conducted, and data derived from the National Physical Activity Survey in Taiwan 2020 were reviewed. The participants included 5,611 men and 5,029 women, aged 23 to 44 years. Each participant completed a computer-assisted telephone interviewing with a standardized, structured questionnaire including sociodemographic characteristics, LTPA behavior, selfreported health status, and self-evaluations (comprising height, body weight, and happiness).

Results: By using multiple regression, after potential confounders adjustment, we observed that regular LTPA was significantly associated with happiness scores for men $(\beta=0.043, p=0.001)$ and women $(\beta=$ $0.050, p<0.0001)$. Furthermore, multiple logistic regression results indicated that with the non-regular LTPA as a baseline, significant associations were observed both for men (odds ratio [OR] $=1.410,95 \% \mathrm{Cl}$ : $1.173-1.693, p<0.0001)$ and women $(\mathrm{OR}=1.424,95 \% \mathrm{Cl}: 1.169-1.735, p<0.0001)$ at regular LTPA.

Conclusions: The current study suggested that regular LTPA, potentially improve the occurrence of happiness among young men. Moreover, this positive effect of regular LTPA was observed for the occurrence of happiness in young women.

\section{Introduction}

Physical activity (PA) is an essential factor in the prevention and management of mental disorders, such as depression, anxiety, and posttraumatic stress disorder. PA also delays the onset of dementia and can help individuals maintain a healthy weight [1-5]. However, physical inactivity has increased, resulting in a growth in the global burden of noncommunicable diseases [6].

The main cause of the global burden of disease is poor mental health and low happiness [7]. Happiness generally refers to the positive mental or emotional states of joy and satisfaction [8,9], and it has become a public health priority in some countries, as evidenced in a WHO report. The WHO indicated that countries such as the United Kingdom, France, and Canada have complemented measures of population and development, such as gross domestic product [10], with happiness indices.

Although studies in several countries have demonstrated that PA for leisure is more strongly associated with mental health than with other domains, these studies have not explored the definition of happiness [11-13]. In addition, few studies have investigated the mechanism of the relationship among different types of PA (i.e., work related, leisure-time, household), PA intensity (i.e. sedentary, light, moderate, and vigorous), and happiness [14]. Therefore, this study evaluated the relationship between regular leisuretime PA (LTPA) and happiness on the basis of other studies.

\section{Material And Methods}




\subsection{Study sample and data collection procedure}

Cross-sectional nationwide data were obtained from the National Physical Activity Survey in Taiwan (NPAST) of children and adolescents (aged 13-17 years), adults (aged 18-64 years), and older adults (aged 65 years and older) conducted by the Sports Administration of the Ministry of Education of Taiwan. Participants were recruited using random digit dialing to collect a proportionate stratified sample based on multiple factors (e.g., age, gender, and geographic location) and in accordance with the procedure described by Ku et al. [15]. Citizens aged over 13 years from 22 cities and counties in Taiwan were selected as participants. The sample size of each city and county was determined by the proportion of its population to the population of Taiwan. The total sample size was 25,526 in 2020 , with a sampling error of $3-5 \%$ and a $95 \%$ confidence interval $(\mathrm{Cl})$, which allowed for a sufficient sample size and statistical power. Computer-assisted telephone interviewing (CATI) was conducted from August to October 2020. To ensure the quality of the data, a group of well-trained and experienced interviewers were employed to conduct CATI. Data on sociodemographic characteristics (i.e., age, gender, education, and occupation), LTPA behavior, self-reported health status, self-evaluations (e.g., height, weight, and happiness), and zip code of residence were collected. A total of 10,802 young adults (aged 23-44 years) were enrolled. The participants were informed of the objectives, procedures, and contents of this study. This study was conducted in accordance with the Declaration of Helsinki, and all procedures were approved by the Institutional Review Board of Fu Jen Catholic University in Taiwan (FJU-IRB C109085). Oral consent was given before the interviews. All information was contained in a deidentified secondary data set and was released for public research purposes.

\subsection{Variables}

The following demographic characteristics were recorded: age, gender, education level, occupation, and self-reported health status. The participants were divided into age groups of 18-24, 25-29, 30-34, 3539 , and 40-44 years, and in terms of education level, they were divided into elementary school or lower, junior or senior high school, and college or higher groups. Occupation was categorized as white collar, government servant, blue collar, owner or manager, specialist, student, housewife, retired, freelancer, unemployed, and other. Self-reported health status was categorized as excellent, fair, and poor.

Anthropometric variables were obtained from the participants' self-reported height and weight, and body mass index $\left(\mathrm{BMI}, \mathrm{kg} / \mathrm{m}^{2}\right)$ was calculated. Weight classes were defined in accordance with the classification system of the Taiwan Ministry of Health and Welfare Health Promotion Administration as follows: underweight $\left(\mathrm{BMI}<18.5 \mathrm{~kg} / \mathrm{m}^{2}\right)$; normal weight $\left(18.5 \leq \mathrm{BMl}<24 \mathrm{~kg} / \mathrm{m}^{2}\right)$; overweight $(24 \leq \mathrm{BMI}$ $\left.<27 \mathrm{~kg} / \mathrm{m}^{2}\right)$; and obese $\left(\mathrm{BMI} \geq 27 \mathrm{~kg} / \mathrm{m}^{2}\right)$ [16].

\subsection{LTPA}

Questions were posed during CATI to determine whether the participants engaged in regular or nonregular LTPA. First, the participant's engagement in LTPA was determined by asking, "Have you engaged in LTPA in the past month?" Second, if the participant answered affirmatively, the frequency and duration of LTPA 
were determined by asking, "How many times do you engage in LTPA per week?" and "How many minutes do you usually spend at a time?" Third, the intensity of LTPA was assessed by the participants' descriptions of their breathing and sweating in their response to the question "When you are engaging in LTPA, you usually feel..." The participants selected one of the following responses: "No changes in my breath and sweating," "I breathe faster but do not sweat," "I breathe normally but sweat," and "I breathe quickly and sweat." If a participant indicated that they usually breathe quickly and sweat, their LTPA was considered to be of a moderate intensity. Finally, the regular and nonregular LTPA groups were defined on the basis of the following conditions. (1) Regular LTPA group: participants who reported breathing quickly and sweating while engaging in 150-300 minutes of moderate-intensity LTPA or 75-150 minutes of vigorous LTPA per week; (2) nonregular LTPA group: the rest of the participants.

\subsection{Happiness}

Studies have offered a range of definitions for happiness and its determinants [17-20]. Several methods are used to measure happiness, such the Oxford Happiness Inventory [21] and the Satisfaction with Life Scale [22]. These methods usually consist of a single-item (i.e., "All things considered, in general, how happy would you say you are?") to measure happiness in the LTPA domain [23-28]. This item has been validated $[29,30]$ and tested for its temporal stability (test-retest reliability; $r=0.86$; [31]). In the 2020 NPAST, happiness was measured using this item and scored on a 5-point scale from 1 (very unhappy) to 5 (very happy). To collect binary data, the respondents were dichotomized into "happy" (i.e., very happy, happy, and fair) and "unhappy" (i.e., unhappy and very unhappy) groups in accordance with the protocol used in another study [32].

\subsection{Statistical analysis}

Data were analyzed using SAS (version 9.4, SAS Institute, Cary, NC, United States). Continuous variables were analyzed using Student's t-test, and categorical variables were analyzed using the chi-squared test. A multiple linear regression analysis with happiness score as the dependent variable was performed to examine the association between regular LTPA and happiness scores after adjustment for potential confounders. Adjusted odds ratios (ORs) with $95 \% \mathrm{Cls}$ for happiness were calculated from unconditional logistic regression models for regular LTPA. In this study, the test values were presented as means \pm standard deviations or frequency (\%), and the results were evaluated using a two-tailed test, with statistical significance at $p<0.05$.

\section{Results}

Table 1 presents the demographic characteristics of the participants. A total of 10,802 young adults were dichotomized into groups in terms of frequency, intensity, and time of engagement in LTPA. Over $20 \%$ of the participants were classified into the regular LTPA group; this group exhibited a higher proportion of men (65.5\%), normal weight (56.9\%), and higher levels of education (78.6\% holding a college degree or higher). Approximately $0 \%$ were retired, and $85.0 \%$ self-reported that they were in excellent or good health. 
Except for BMI, significant differences were observed across all demographic characteristics between the two groups. 
Table 1

Demographic characteristics

\begin{tabular}{|c|c|c|c|}
\hline \multirow[t]{3}{*}{ Variables } & \multicolumn{2}{|l|}{ LTPA Status } & \multirow[t]{3}{*}{$p$-value } \\
\hline & Regular LTPA & Non-regular LTPA & \\
\hline & $(n=2,592)$ & $(n=8,210)$ & \\
\hline Age (y) & & & $<0.0001^{*}$ \\
\hline $18-24$ & 809 (31.20\%) & $1598(19.50 \%)$ & \\
\hline $25-29$ & $480(18.50 \%)$ & $1412(17.20 \%)$ & \\
\hline $30-34$ & $443(17.10 \%)$ & $1429(17.40 \%)$ & \\
\hline $35-39$ & $403(15.50 \%)$ & $1880(22.90 \%)$ & \\
\hline $40-44$ & $457(17.60 \%)$ & $1891(23.00 \%)$ & \\
\hline Gender (\% men) & $1,698(65.5 \%)$ & $4,001(48.7 \%)$ & $<0.0001^{*}$ \\
\hline Height (cm) & $169.26 \pm 8.68$ & $165.75 \pm 8.31$ & $<0.0001^{*}$ \\
\hline Body weight (kg) & $66.49 \pm 13.26$ & $63.80 \pm 14.07$ & $<0.0001^{*}$ \\
\hline BMI $\left(\mathrm{kg} / \mathrm{m}^{2}\right)$ & $23.08 \pm 3.55$ & $23.07 \pm 4.05$ & 0.960 \\
\hline Obese Status (\%) & & & $<0.0001^{*}$ \\
\hline Underweight & $184(7.10 \%)$ & $737(9.00 \%)$ & \\
\hline Normal weight & $1475(56.90 \%)$ & $4285(52.20 \%)$ & \\
\hline Overweight & $485(18.70 \%)$ & $1598(19.50 \%)$ & \\
\hline Obese & $353(13.60 \%)$ & $1230(15.00 \%)$ & \\
\hline Education (\%) & & & $<0.0001 *$ \\
\hline Elementary school or lower & $2(0.10 \%)$ & $30(0.40 \%)$ & \\
\hline Junior or senior school & $553(21.40 \%)$ & $2547(31.10 \%)$ & \\
\hline College or higher & $2035(78.60 \%)$ & $5608(68.50 \%)$ & \\
\hline Occupation (\%) & & & $<0.0001 *$ \\
\hline White collar & $588(22.80 \%)$ & $2033(24.90 \%)$ & \\
\hline
\end{tabular}

Abbreviations: BMI, body mass index; LTPA, leisure-time physical activity.

${ }^{*} p<0.05$

aValues expressed as means \pm standard deviation for continuous variables. 


\begin{tabular}{|c|c|c|c|}
\hline Variables & LTPA Status & & p-value \\
\hline Government servant & $228(8.80 \%)$ & $497(6.10 \%)$ & \\
\hline Blue collar & $380(14.70 \%)$ & $1970(24.10 \%)$ & \\
\hline Owner/manager & $139(5.40 \%)$ & $337(4.10 \%)$ & \\
\hline Specialists & $289(11.20 \%)$ & $812(10.00 \%)$ & \\
\hline Student & $616(23.90 \%)$ & $895(11.00 \%)$ & \\
\hline Housewife & $80(3.10 \%)$ & $641(7.90 \%)$ & \\
\hline Retired & $1(0.00 \%)$ & $13(0.20 \%)$ & \\
\hline Free lancer & $104(4.00 \%)$ & $248(3.00 \%)$ & \\
\hline Jobless & $119(4.60 \%)$ & $636(7.80 \%)$ & \\
\hline Other & $36(1.40 \%)$ & $78(1.00 \%)$ & \\
\hline Self-reported health status (\%) & & & $<0.0001^{\star}$ \\
\hline Excellent or good & $2185(85.00 \%)$ & $6071(75.50 \%)$ & \\
\hline Fair & $103(4.00 \%)$ & $520(6.50 \%)$ & \\
\hline Very bad or poor & $282(11.00 \%)$ & $1449(18.00 \%)$ & \\
\hline \multicolumn{4}{|c|}{ Abbreviations: BMI, body mass index; LTPA, leisure-time physical activity. } \\
\hline${ }^{\star} p<0.05$ & & & \\
\hline
\end{tabular}

Table 2 presents a comparison of the happiness scores between the young adults in the regular LTPA and nonregular LTPA groups. In terms of gender, a significant difference was observed between the LTPA status and happiness of men in two age groups ( $18-24$ and 30-34 years; $p<0.05)$ and that of women aged 25-39 years. A significant difference was observed between LTPA status and happiness in the 1824 and $30-34$ age group $(p<0.005)$ when the groups were pooled. 
Table 2

Happiness scores of Taiwanese young adults in regular and non-regular LTPA groups

\begin{tabular}{|c|c|c|c|}
\hline \multirow[t]{2}{*}{ Variables } & \multicolumn{2}{|l|}{ LTPA Status } & \multirow[t]{2}{*}{ P-value } \\
\hline & Regular LTPA & Non-regular LTPA & \\
\hline \multicolumn{4}{|c|}{$\operatorname{Men}(n=5,611)$} \\
\hline $18-24$ & $4.02 \pm 0.53$ & $3.88 \pm 0.64$ & $<0.0001^{\star}$ \\
\hline $25-29$ & $3.80 \pm 0.75$ & $3.84 \pm 0.64$ & 0.341 \\
\hline $30-34$ & $3.95 \pm 0.59$ & $3.74 \pm 0.82$ & $<0.0001^{\star}$ \\
\hline $35-39$ & $3.82 \pm 0.69$ & $3.78 \pm 0.73$ & 0.497 \\
\hline $40-44$ & $3.75 \pm 0.75$ & $3.76 \pm 0.71$ & 0.943 \\
\hline \multicolumn{4}{|c|}{ Women $(n=5,029)$} \\
\hline $18-24$ & $4.05 \pm 0.56$ & $3.99 \pm 0.54$ & 0.131 \\
\hline $25-29$ & $3.96 \pm 0.41$ & $3.83 \pm 0.60$ & $0.001^{*}$ \\
\hline $30-34$ & $3.92 \pm 0.46$ & $3.81 \pm 0.69$ & $0.017^{\star}$ \\
\hline $35-39$ & $3.91 \pm 0.62$ & $3.76 \pm 0.72$ & $0.004^{\star}$ \\
\hline $40-44$ & $3.86 \pm 0.61$ & $3.80 \pm 0.68$ & 0.246 \\
\hline \multicolumn{4}{|c|}{ Total $(n=10,640)$} \\
\hline $18-24$ & $4.03 \pm 0.54$ & $3.94 \pm 0.60$ & $<0.0001^{\star}$ \\
\hline $25-29$ & $3.85 \pm 0.66$ & $3.84 \pm 0.62$ & 0.624 \\
\hline $30-34$ & $3.94 \pm 0.56$ & $3.78 \pm 0.75$ & $<0.0001^{*}$ \\
\hline $35-39$ & $3.86 \pm 0.66$ & $3.77 \pm 0.73$ & $0.018^{*}$ \\
\hline $40-44$ & $3.80 \pm 0.70$ & $3.78 \pm 0.69$ & 0.721 \\
\hline
\end{tabular}

Table 3 presents the results of the comparison of happiness between young adults in the regular and nonregular LTPA groups. A significant difference in happiness was observed between men and women in both the regular LTPA and nonregular LTPA groups, but this difference was across different age groups ( $p$ $<0.05)$. However, a significant difference in happiness was observed between two age groups of men in the both regular LTPA and nonregular LTPA groups (18-24 and 30-34 years). A significant difference in happiness was observed between two ages groups of women in both the regular LTPA and nonregular 
LTPA groups (30-34 and 35-39 years). In addition, in both the regular LTPA and nonregular LTPA groups, unhappiness was more prevalent than happiness. Moreover, when the groups were pooled, the results indicated a significant difference in happiness among three age groups in both the regular LTPA and nonregular LTPA groups (18-24, 30-34, and 35-39 years). 
Table 3

Prevalence of happiness and unhappiness in Taiwanese young adults in regular and non-regular LTPA groups

\begin{tabular}{|c|c|c|c|c|}
\hline \multicolumn{2}{|c|}{ Variables } & \multicolumn{2}{|l|}{ LTPA Status } & \multirow[t]{2}{*}{ p-value } \\
\hline & & \multirow[t]{2}{*}{ Regular LTPA } & \multirow[t]{2}{*}{ Non-regular LTPA } & \\
\hline \multicolumn{3}{|c|}{ Men $(n=5,611)$} & & \\
\hline \multirow[t]{2}{*}{$18-24$} & Happy & $36(6.50 \%)$ & $101(12.50 \%)$ & $<0.0001^{*}$ \\
\hline & Unhappy & $517(93.50 \%)$ & 704 (87.50\%) & \\
\hline \multirow[t]{2}{*}{$25-29$} & Happy & $52(16.90 \%)$ & 100 (12.90\%) & 0.087 \\
\hline & Unhappy & $256(83.10 \%)$ & $676(87.10 \%)$ & \\
\hline \multirow[t]{2}{*}{$30-34$} & Happy & $35(11.30 \%)$ & $127(19.30 \%)$ & $0.002^{\star}$ \\
\hline & Unhappy & $274(88.70 \%)$ & $530(80.70 \%)$ & \\
\hline \multirow[t]{2}{*}{$35-39$} & Happy & $34(14.20 \%)$ & $150(17.30 \%)$ & 0.246 \\
\hline & Unhappy & $206(85.80 \%)$ & $716(82.70 \%)$ & \\
\hline \multirow[t]{2}{*}{$40-44$} & Happy & $41(15.00 \%)$ & $165(20.00 \%)$ & 0.066 \\
\hline & Unhappy & $232(85.00 \%)$ & $659(80.00 \%)$ & \\
\hline \multicolumn{5}{|c|}{ Women $(n=5,029)$} \\
\hline \multirow[t]{2}{*}{$18-24$} & Happy & $16(6.30 \%)$ & $51(6.50 \%)$ & 0.911 \\
\hline & Unhappy & $239(93.70 \%)$ & 737 (93.50\%) & \\
\hline \multirow[t]{2}{*}{$25-29$} & Happy & $16(9.50 \%)$ & $89(14.30 \%)$ & 0.099 \\
\hline & Unhappy & $153(90.50 \%)$ & $532(85.70 \%)$ & \\
\hline \multirow[t]{2}{*}{$30-34$} & Happy & $11(8.60 \%)$ & $127(16.90 \%)$ & $0.017 \star$ \\
\hline & Unhappy & $117(91.40 \%)$ & $624(83.10 \%)$ & \\
\hline \multirow[t]{2}{*}{$35-39$} & Happy & $17(10.40 \%)$ & $162(17.10 \%)$ & $0.032^{\star}$ \\
\hline & Unhappy & $146(89.60 \%)$ & $784(82.90 \%)$ & \\
\hline \multirow[t]{2}{*}{$40-44$} & Happy & $22(12.70 \%)$ & 170 (16.40\%) & 0.220 \\
\hline & Unhappy & $151(87.30 \%)$ & 867 (83.60\%) & \\
\hline
\end{tabular}

Abbreviations: LTPA, leisure-time physical activity.

${ }^{*} p<0.05$ 


\begin{tabular}{|c|c|c|c|c|}
\hline \multicolumn{2}{|c|}{ Variables } & \multicolumn{2}{|l|}{ LTPA Status } & \multirow[t]{2}{*}{ p-value } \\
\hline & & Regular LTPA & Non-regular LTPA & \\
\hline \multirow[t]{2}{*}{$18-24$} & Happy & $52(6.40 \%)$ & $152(9.50 \%)$ & $0.010^{*}$ \\
\hline & Unhappy & 756 (93.60\%) & $1441(90.50 \%)$ & \\
\hline \multirow[t]{2}{*}{$25-29$} & Happy & $68(14.30 \%)$ & $189(13.50 \%)$ & 0.679 \\
\hline & Unhappy & $408(85.70 \%)$ & $1208(86.50 \%)$ & \\
\hline \multirow[t]{2}{*}{$30-34$} & Happy & $46(10.50 \%)$ & $254(18.00 \%)$ & $<0.0001^{\star}$ \\
\hline & Unhappy & 391 (89.50\%) & $1154(82.00 \%)$ & \\
\hline \multirow[t]{2}{*}{$35-39$} & Happy & $51(12.70 \%)$ & $313(17.30 \%)$ & $0.025^{\star}$ \\
\hline & Unhappy & $351(87.30 \%)$ & $1500(82.70 \%)$ & \\
\hline \multirow[t]{2}{*}{$40-44$} & Happy & $63(14.10 \%)$ & $335(18.00 \%)$ & 0.051 \\
\hline & Unhappy & 383 (85.90\%) & $1525(82.00 \%)$ & \\
\hline \multicolumn{5}{|c|}{ Abbreviations: LTPA, leisure-time physical activity. } \\
\hline \multicolumn{5}{|c|}{${ }^{*} p<0.05$} \\
\hline
\end{tabular}

Table 4 presents the results of the multivariate regression analysis of the relationship between regular LTPA and happiness scores. The results indicated a positive association between regular LTPA and happiness $(p<0.05)$. However, after adjustment for age, BMI, self-reported health status, occupation, and education, the regression coefficients of each variable decreased (men, $\beta=0.043$; women, $\beta=0.050$; total, $\beta=0.043)$. 
Table 4

Multivariate regression analysis of the association between regular LTPA and happiness scores

\begin{tabular}{|c|c|c|c|c|c|c|}
\hline \multirow[t]{2}{*}{ Variables } & \multicolumn{3}{|c|}{ Model 1 (unadjusted) } & \multicolumn{3}{|c|}{ Model 2 (adjusted $^{a}$ ) } \\
\hline & $\boldsymbol{\beta}$ & SE & p-value & $\beta$ & SE & p-value \\
\hline \multicolumn{7}{|l|}{ Men } \\
\hline Regular LTPA & 0.067 & 0.023 & $<0.0001^{\star}$ & 0.043 & 0.022 & $0.001^{\star}$ \\
\hline Non-regular LTPA & Ref. & - & - & Ref. & - & - \\
\hline \multicolumn{7}{|l|}{ Women } \\
\hline Regular LTPA & 0.065 & 0.022 & $<0.0001^{*}$ & 0.050 & 0.022 & $<0.0001 *$ \\
\hline Non-regular LTPA & Ref. & - & - & Ref. & - & - \\
\hline \multicolumn{7}{|l|}{ Total } \\
\hline Regular LTPA & 0.063 & 0.016 & $<0.0001^{\star}$ & 0.043 & 0.016 & $<0.0001^{\star}$ \\
\hline Non-regular LTPA & Ref. & - & - & Ref. & - & - \\
\hline \multicolumn{7}{|c|}{ Abbreviations: LTPA, leisure-time physical activity; SE, standard error. } \\
\hline \multicolumn{7}{|l|}{${ }^{*} p<0.05$} \\
\hline
\end{tabular}

In the multivariate analysis (Table 5), regular LTPA was most strongly associated with increased happiness, and the significant associations were observed in men, women, and total participants $(p<$ 0.05). However, after adjustment for age, BMI, self-reported health status, occupation, and education, the associations between happiness and each variable were strong (men, $O R=1.41$; women, $O R=1.424$; total, $\mathrm{OR}=1.392$ ). 
Table 5

Multivariate logistic regression analysis of the association between regular LTPA and happiness Variables Model 1 (unadjusted)

Model 2 (adjusted $\left.{ }^{a}\right)$

\begin{tabular}{|c|c|c|c|c|c|c|}
\hline & OR & $95 \% \mathrm{Cl}$ & $p$-value & OR & $95 \% \mathrm{Cl}$ & $p$-value \\
\hline \multicolumn{7}{|l|}{ Men } \\
\hline Regular LTPA & 1.571 & $1.323-1.866$ & $<0.0001^{\star}$ & 1.410 & $1.173-1.693$ & $<0.0001 *$ \\
\hline Non-regular LTPA & Ref. & - & - & Ref. & - & - \\
\hline \multicolumn{7}{|l|}{ Women } \\
\hline Regular LTPA & 1.592 & $1.318-1.923$ & $<0.0001^{\star}$ & 1.424 & $1.169-1.735$ & $<0.0001^{*}$ \\
\hline Non-regular LTPA & Ref. & - & - & Ref. & - & - \\
\hline \multicolumn{7}{|l|}{ Total } \\
\hline Regular LTPA & 1.557 & $1.371-1.767$ & $<0.0001^{\star}$ & 1.392 & $1.218-1.592$ & $<0.0001^{*}$ \\
\hline Non-regular LTPA & Ref. & - & - & Ref. & - & - \\
\hline \multicolumn{7}{|c|}{ Abbreviations: $\mathrm{Cl}$, confidence interval; LTPA, leisure-time physical activity; OR, odds ratio. } \\
\hline \multicolumn{7}{|l|}{${ }^{*} p<0.05}$. \\
\hline
\end{tabular}

\section{Discussion}

This study evaluated the association between regular LTPA and happiness. The results indicated a positive association between regular LTPA and happiness. In addition, regular LTPA compared with nonregular LTPA group was most strongly associated with increased happiness, and happiness was associated with gender (men, women, and total).

Studies on the association between happiness and LTPA in young populations have yielded similar results. Rasmussen and Laumann [33] evaluated PA using a single item and indicated that PA was positively associated with happiness in young adults (mean age $=24.86$ years) [34]. The study revealed that PA is positively correlated with well-being and that the correlation is specific to walking and vigorous PA [28]. In addition, research involving college students [35] has indicated that PA frequency was positively associated with happiness. The FITT (frequency, intensity, time, and type) of the LTPA covariates used to adjust the association between PA and happiness must be acknowledged.

Because this study had several limitations, the results should be interpreted carefully. First, because this study used a secondary database, other potential confounding factors, such as chronic diseases or mental disorders, could not be investigated. Future research should investigate other key variables and 
eliminate potential confounding factors. Second, this study adopted a cross-sectional design; therefore, the lack of longitudinal data challenges the inference of the causal relationship. Third, although this study examined LTPA, most of the participants were highly active in society. Therefore, their levels of work-related PA may also be higher than those of other ages, which may have affected the results of this study. Therefore, different correlation variables should be considered for different age groups.

\section{Conclusion}

This study demonstrated that regular LTPA were key factors affecting happiness. LTPA is essential for relaxation. For young adults, regular LTPA is crucial to mental health. Therefore, they should engage in higher-intensity LTPA for longer periods of time. Further research is required to determine whether different FITTs of PA are more effective predictors of happiness than LTPA for young adults; such research can also identify the type of PA that is most effective in increasing happiness.

\section{Abbreviations}

BMI: body mass index; CATI: computer-assisted telephone interviewing; Cl: confidence interval; FITT: frequency, intensity, time, and type; LTPA: leisure-time physical activity; NPAST: National Physical Activity Survey in Taiwan; OR: odds ratio; PA: physical activity; WHO: World Health Organization.

\section{Declarations}

\section{Ethics approval and consent to participate}

This study was conducted with a secondary database provided by the Sports Cloud: Information and Application Research Center of Sports for All, Sport Administration, Ministry of Education in Taiwan. All consents obtained from the study participants were written prior the data collection. This study's design and analysis procedure was approved by the Ethical Committee of Fu Jen Catholic University (FJU-IRB C109085).

\section{Consent for publication}

Not applicable.

\section{Availability of data and materials}

The data that support the findings of this study are available from [the Sports Cloud: Information and Application Research Center of Sports for All, Sport Administration, Ministry of Education in Taiwan] but restrictions apply to the availability of these data, which were used under license for the current study, and so are not publicly available. Data are however available from the authors upon reasonable request and with permission of [the Sports Cloud: Information and Application Research Center of Sports for All, Sport Administration, Ministry of Education in Taiwan]. 


\section{Competing interests}

The authors declare that they have no competing interests.

\section{Funding}

This study was supported by a grant from the Ministry of Science and Technology (MOST 109-2410-H030-059).

\section{Authors' contributions}

$\mathrm{CCH}$ participated in the design, conducted the statistical analyses, interpreted the data, drafted and revised the manuscript. The author has read and agreed to the published version of the manuscript.

\section{Acknowledgements}

This study is based in part on data from the National Physical Fitness Survey provided by the Sports Cloud: Information and Application Research Center of Sports for All, Sport Administration, Ministry of Education in Taiwan. The interpretation and conclusions contained herein do not represent those of Sport Administration, Ministry of Education in Taiwan.

\section{Authors' information}

${ }^{1}$ Department of Physical Education, Fu Jen Catholic University, New Taipei City 242, Taiwan; ${ }^{2}$ Research and Development Center for Physical Education, Health, and Information Technology, Fu Jen Catholic University, New Taipei City 242, Taiwan; ${ }^{3}$ Artificial Intelligence Development Center, Fu Jen Catholic University, New Taipei City, 24205, Taiwan.

\section{References}

1. Physical Activity Guidelines Advisory Committee report, 2008. To the Secretary of Health and Human Services. Part A: executive summary. Nutr Rev, 67 (2009), pp. 114-120.

2. DE Warburton, S Charlesworth, A Ivey, L Nettlefold, SS Bredin. A systematic review of the evidence for Canada's Physical Activity Guidelines for Adults Int J Behav Nutr Phys Act, 7 (2010), p. 39.

3. WHO. Global recommendations on physical activity for health World Health Organization, Geneva (2010).

4. Sallis, J. F., Bull, F., Guthold, R., Heath, G. W., Inoue, S., Kelly, P., ... Lancet Physical Activity Series 2 Executive Committee. (2016). Progress in physical activity over the Olympic quadrennium. The Lancet, 388(10051), 1325-1336.

5. ISPAH International Society for Physical Activity and Health. The Bangkok Declaration on Physical Activity for Global Health and Sustainable Development. Br J Sports Med, 51 (2017), pp. 1389-1391. 
6. Lee IM, Shiroma EJ, Lobelo F, Puska P, Blair SN, Katzmarzyk PT. Effect of physical inactivity on major non- communicable diseases worldwide: an analysis of burden of disease and life expectancy. Lancet. 2012; 380(9838):219-29.

7. Vigo, D., Thornicroft, G., \& Atun, R. (2016). Estimating the true global burden of mental illness. The Lancet Psychiatry, 3(2), 171-178.

8. Asztalos, M., Wijndaele, K., De Bourdeaudhuij, I., Philippaerts, R., Matton, L., Duvigneaud,N., ... Cardon, G. (2012). Sport participation and stress among women and men. Psychology of Sport and Exercise, 13(4), 466-483.

9. Huppert, F. A. (2009). A new approach to reducing disorder and improving well-being. Perspectives on psychological science, 4(1), 108-111.

10. Vaillant, G. (2011). The happiness effect. Bull World Health Organ, 89, 246-247.

11. Hamer M, Stamatakis E, Steptoe A. Dose-response relationship between physical activity and mental health: the Scottish Health Survey. Br J Sports Med. 2009;43(14):1111-4.

12. Stephens T. Physical activity and mental health in the United States and Canada: Evidence from four population surveys. Prev Med. 1988;17(1):35-47.

13. Asztalos, M., Wijndaele, K., De Bourdeaudhuij, I., Philippaerts, R., Matton, L., Duvigneaud,N., ... Cardon, G. (2009). Specific associations between types of physical activity and components of mental health. Journal of science and medicine in sport, 12(4),468-474.

14. Fisher, J. J., Kaitelidou, D., \& Samoutis, G. (2019). Happiness and physical activity levels of first year medical students studying in Cyprus: a cross-sectional survey. BMC medical education, 19(1), 1-7.

15. Ku, P. W., Fox, K. R., McKenna, J., \& Peng, T. L. (2006). Prevalence of leisure-time physical activity in Taiwanese adults: results of four national surveys, 2000-2004. Preventive Medicine, 43(6), 454-457.

16. Health Promotion Administration, Ministry of Health and Welfare. Check Your Body Weight Every Day. Available online: https://www.hpa.gov.tw/Home/Index.aspx (accessed on 15 May 2021).

17. Diener, E. (2000). Subjective well-being: The science of happiness and a proposal for a national index. American psychologist, 55(1), 34.

18. Jalali, Z., \& Heidari, A. (2016). The relationship between happiness, subjective well-being, creativity and job performance of primary school teachers in Ramhormoz city. International Education Studies, $9(6), 45-52$.

19. Myers, D. G., \& Diener, E. (2018). The scientific pursuit of happiness. Perspectives on Psychological Science, 13(2), 218-225.

20. Veenhoven, R. (2010). Greater happiness for a greater number. Journal of happiness studies, 11(5), 605-629.

21. Argyle, M., Martin, M., \& Lu, L. (1995). Testing for stress and happiness: The role of social and cognitive factors. Stress and emotion, 15, 173-187.

22. Diener, E., Horwitz, J., \& Emmons, R. A. (1985). Happiness of the very wealthy. Social indicators research, 16(3), 263-274. 
23. de Souto Barreto, P. (2014). Direct and indirect relationships between physical activity and happiness levels among older adults: a cross-sectional study. Aging \& mental health, 18(7), 861-868.

24. Baruth, M.; Lee, D.C.; Sui, X.; Church, T.S.; Marcus, B.H.; Wilcox, S.; Blair, S.N. Emotional out-look on life predicts increases in physical activity among initially inactive men. Health Educ. Behav. 2011, 38, 150-158.

25. Lera-López, F., Ollo-López, A., \& Sánchez-Santos, J. M. (2021). Is Passive Sport Engagement Positively Associated with Happiness?. Applied Psychology: Health and Well-Being, 13(1), 195-218.

26. Maher, C. A., Toohey, M., \& Ferguson, M. (2016). Physical activity predicts quality of life and happiness in children and adolescents with cerebral palsy. Disability and rehabilitation, 38(9), 865869.

27. Min, J. H., Lee, E.-Y., Spence, J. C., \& Jeon, J. Y. (2017). Physical activity, weight status and psychological well-being among a large national sample of South Korean adolescents. Mental Health and Physical Activity, 12, 44-49.

28. Richards, J., Jiang, X., Kelly, P., Chau, J., Bauman, A., \& Ding, D. (2015). Don't worry, be happy: crosssectional associations between physical activity and happiness in 15 European countries. BMC public health, 15(1), 1-8.

29. Goldberg, D. P., Gater, R., Sartorius, N., Ustun, T. B., Piccinelli, M., Gureje, O., \& Rutter, C. (1997). The validity of two versions of the GHQ in the WHO study of mental illness in general health care. Psychological medicine, 27(1), 191-197.

30. Kye, S. Y., \& Park, K. (2014). Health-related determinants of happiness in Korean adults. International journal of public health, 59(5), 731-738.

31. Abdel-Khalek, A. M. (2006). Measuring happiness with a single-item scale. Social Behavior and Personality: an international journal, 34(2), 139-150.

32. Wang, J.H. Happiness and social exclusion of indigenous peoples in Taiwan-A social sustainability perspective. PLoS ONE 2015, 10, e0118305.

33. Rasmussen, M., \& Laumann, K. (2014). The role of exercise during adolescence on adult happiness and mood. Leisure Studies, 33(4), 341-356.

34. Lathia, N., Sandstrom, G. M., Mascolo, C., \& Rentfrow, P. J. (2017). Happier people live more active lives: Using smartphones to link happiness and physical activity. PLoS ONE, 12(1), e0160589

35. Piqueras, J. A., Kuhne, W., Vera-Villarroel, P., Van Straten, A., \& Cuijpers, P. (2011). Happiness and health behaviours in Chilean college students: A cross-sectional survey. BMC Public Health, 11(1), 443. 